\title{
A Review on Organic Food Production in Malaysia
}

\author{
Chandran Somasundram *, Zuliana Razali and Vicknesha Santhirasegaram \\ Institute of Biological Sciences \& Centre for Research in Biotechnology for Agriculture (CEBAR), \\ Faculty of Science, University of Malaya, Kuala Lumpur 50603, Malaysia; zuliana@um.edu.my (Z.R.); \\ vicknesha19@gmail.com (V.S.) \\ * Correspondence: chandran@um.edu.my; Tel.: +60-3-7967-4423; Fax: +60-3-7967-4178 \\ Academic Editor: Douglas D. Archbold \\ Received: 1 December 2015; Accepted: 20 August 2016; Published: 24 August 2016
}

\begin{abstract}
The consumption of organic food has grown remarkably, both in developed and developing countries. Although organic food comprises only a small fraction of the food market, its rapid growth has generated much interest among consumers and businesses, as well as researchers. For products to be called organic, the production must conform to a certain established organic standard and be certified by a recognized certifying body. In Malaysia, the local organic food industry is still small, as more than $60 \%$ of organic food products are imported. Most of the organic products are sold domestically, while some are exported to Singapore. The perception and understanding of organic food production is based mainly on not using synthetic fertilizers and pesticides. In general, there is a lack of awareness among producers, retailers, and consumers of the wider extent of organic production and processing standards in local markets. The organic food industry is facing several challenges in Malaysia. Although the demand for organic food in Malaysia is growing, the supply of local organic products is not able to keep up with the increased demand. In addition to the inconsistent supply, the variety of local organic food is also limited. Another problem faced by local organic food consumers is the price difference between organic and conventional food. Hence, to match the recent increases in demand, the Malaysian Agricultural Research and Development Institute is actively developing the organic farming sector through various programs and activities.
\end{abstract}

Keywords: organic; food; production; consumers and Malaysia

\section{Introduction}

Consumers worldwide are increasingly concerned about nutrition, health, and the quality of their food. Major concerns have appeared because of recurrent food crises involving pesticide residues on fresh produce, food contamination by chemicals in dairy and seafood products, and the unregulated use of additives in processed foods. With health-related problems such as obesity, type 2 diabetes, and coronary heart disease on the rise, consumers are becoming more aware of the effects of their eating habits on their health. In addition, the increase in environmental awareness and threats posed by pesticide use are also related to the growing interest in organic food production. As a result, organic food is perceived as safer by consumers because they believe it is chemical-free when compared to products from conventional farming. Therefore, health can be considered as an important factor and has a positive relationship to consumers' decision to buy organic food [1].

Although organic food comprises only a small fraction of the food market, its rapid growth has generated much interest among consumers and businesses, as well as researchers. The demand for organic food has increased tremendously, especially in developed countries. This trend has also moved to developing countries, including Malaysia. The movement towards organic food is reflected by the increasing number of countries producing organic food and the increase in total sales [2].

Due to growing organic food product development, it is important to identify the issues and challenges associated with organic food production in Malaysia. This review will provide an overview 
of issues related to the organic food industry, organic certification, and the challenges faced by the emerging organic food industry. This information is needed to enhance the level of awareness and marketing strategies that could be adopted to improve organic food products in the country.

\section{Organic Food Industry}

\subsection{Organic Agriculture and Food}

Organic agriculture improves agro-ecosystem health, including biodiversity, biological cycles, and soil biological activity. It emphasizes the use of cultural, biological, and mechanical practices as opposed to using synthetic materials to fulfil any specific functions within the system. It promotes the health of soil, water, and air by minimizing all forms of pollution that may result from agricultural practices. Hence, organic agriculture is an integrated farming approach which gives importance to both technical and economic aspects, as well as human health [3].

The National Organic Standards Board of the U.S. Department of Agriculture established a national standard for the term "organic" in December 2000. Organic food is produced by farmers who emphasize the use of renewable resources and the conservation of soil and water to enhance environmental quality for future generations. Organic meat, poultry, eggs, and dairy products come from animals that are given no antibiotics or growth hormones. Organic food is produced without the use of most conventional pesticides, synthetic fertilizers, bioengineering, or ionizing radiation. For products to be called organic, the production must conform to a certain established organic standard and be certified by a recognized certifying body [3,4].

\subsection{Status of the Global Market}

According to the latest survey by The Research Institute of Organic Agriculture (FiBL) and the International Federation of Organic Agriculture Movements (IFOAM) in 2015, there were 43.1 million hectares (ha) of organic agricultural land in 2013. The regions with the largest areas of organic agricultural land are Oceania (40\%), Europe (27\%), and Latin America (15\%). Asia contributed $8 \%$ to the world's agricultural land, followed by North America (7\%) and Africa (3\%).

There were almost 2 million producers in 2013. Thirty-six percent of the world's organic producers are in Asia, followed by Africa (29\%) and Europe (17\%). About a quarter of the world's agricultural land (11.7 million ha) and more than 80\% (1.7 million ha) of the producers are in developing countries and emerging markets. Global sales of organic food reached 72 billion U.S. dollars in 2013. As shown in Figure 1, revenues have increased almost five-fold since 1999. The growth of organic product sales has consistently increased over the last decade [5].

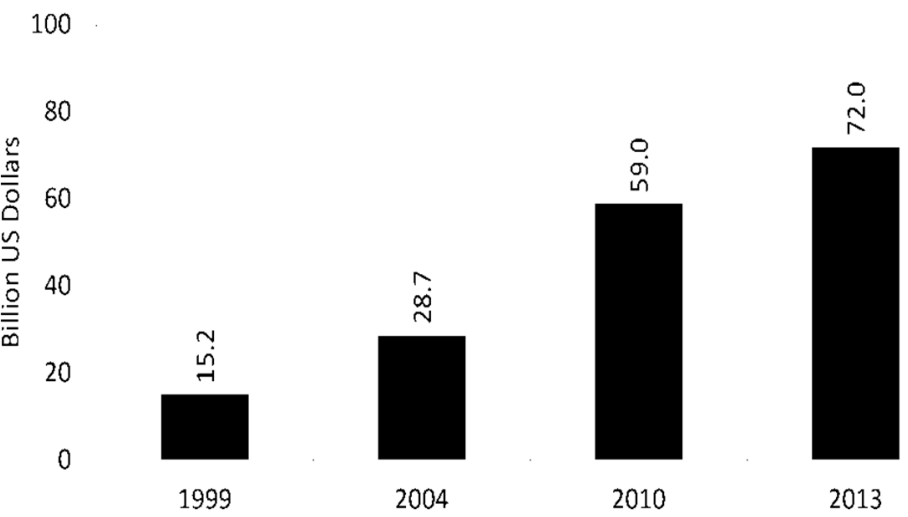

Figure 1. Growth of the global market for organic food, 1999-2013 (Source: [5]). 


\subsection{The Malaysian Scenario}

\subsubsection{Organic Food Production and Market}

Organic agriculture in Malaysia has developed on two concurrent paths, led by non-governmental organizations (NGOs) and the private sector. The Centre for Environment, Technology and Development Malaysia (CETDEM) is an example of an NGO that has played a pioneering and prominent role in identifying problems with conventional agricultural practices. CETDEM has focused on environment degradation, the health of plantation workers from pesticide use, food safety, and sustainable agriculture. However, it was only in the 1990s that many pioneering organic farms were established, such as those in Penang and Kuantan, Sustainable Living Centre in Perak, Lifestyle farmhouse in Melaka, Ecofarm in Negeri Sembilan, and Nakim Farm in Negeri Sembilan.

Currently, organic food remains a niche market, but one that is slowly growing. In 2001, only 131 ha in Malaysia were organic farms. In a span of just five years, the land area for organic farms grew by an incredible 18-fold to 2367 ha, of which 962 ha are certified organic, as surveyed by the FiBL and the German Foundation Ecology \& Farming (SOEL) in 2007. In 2001, the Malaysian Department of Agriculture (DOA) reported that there were 27 organic producers in the country. In East Malaysia, the production of organic products is limited to vegetables and fruit. In 2013, the DOA reported that there was a total of 89 farms occupying 1634 ha of land under organic farming and 49 farmers had valid certification. In Malaysia, the local organic food industry is still small, as more than $60 \%$ of organic food products are imported. Most of the organic products are sold domestically, while some are exported to Singapore $[1,2,6]$.

The Third National Agriculture Policy (NAP3) realized a key benefit of organic farming-export opportunities in the niche organic market that could bring high revenue to the country. One of the strategies undertaken by the government to realize this plan was to encourage small-scale producers to participate in organic farming. It has also been the government's strategy to increase producers' incomes. In the ninth Malaysia Plan (2006-2010), the government targeted organic farming, which was reported to have a potential value of more than U.S. $\$ 200$ million over 5 years. The Ministry of Agriculture planned to have 20,000 ha of organic farms by 2010 and to increase local production by 4000 ha per year [6,7].

The hub of vegetable farming in Malaysia can be found in Cameron Highlands, where Grace Cup Pte Ltd. (Pahang, Malaysia) and Cameron Organic Produce Pte Ltd. (Pahang, Malaysia) have established organic vegetable farms. Large local organic retailers, such as Country Farm Organics and Zenxin have established a foothold in selling and distributing organic food. The distribution of organic food in Malaysia has been fragmented due to the existence of specialty shops which operate all over the country. About $70 \%$ of the organic food products have been distributed through specialized organic food stores and supermarket chains. The balance has been distributed through traditional retail shops, wet markets, or home deliveries [7].

\subsubsection{Organic Certification and Standards}

The Malaysian government has also introduced national standards for organic farming and organic foods. In 2002, the Malaysian DOA outlined national standards and a government certification program. The scheme was revised and renamed the Malaysia Organic Scheme (MOS) in 2003. Organic products produced according to the MS 1529 national standard display the Organic Malaysia logo. The MOS is limited in that it only covers plant-based products, whereas livestock products and processed foods are not yet included [2,3].

The Scheme is open for participation by all farmers who are engaged in the primary production of fresh organic food products. A group of trained agricultural officers has been assigned to carry out field inspection to verify that the farm operations or practices are in compliance with the organic standards. In 2002, the Ministry of Agriculture noted that support services such as extension, research, and development would be devoted to developing organic agriculture in Malaysia. Export of certified 
organic food also depends on the laws of the receiving country. Presently, more than 70 farmers have MOS accreditation to produce organic products for the local as well as the export market $[2,6]$.

\subsubsection{Challenges and Alternatives}

The organic food industry is facing several challenges in Malaysia. Although the demand for organic food is growing, the supply of local organic product is not keeping up with the increased demand. Aside from an inconsistent supply, the variety of local organic food is also limited. Consequently, Malaysia still needs to heavily import organic food products from other countries, especially from the United States, Japan, Australia, New Zealand, and China [2,7].

Another problem faced by local organic food consumers is the price difference between organic and conventional food. Although it is well known that organic food is more expensive than conventional food, their price difference in Malaysia is particularly substantial—by as much as $100 \%$ to $300 \%$ - compared to only a $25 \%$ to $30 \%$ price gap in the United States and European Union (EU). The higher price results from the higher cost of production, especially labour costs and the loss of income or opportunity costs when farmers convert their conventional farms to organic farms. The concern a customer has for the environment may drive them to purchase an organic product; however, the high prices may limit their ability to buy the product. Conversely, there is still an increased demand for organic product globally, despite the price. This is mainly due to the potential of increased nutritional value and/or reduced food safety risks $[2,8]$.

Finally, there is still a distinct lack of trust among consumers towards produce that is labelled "organic", even with the Government's certification efforts. More needs to be done to overcome the prevailing issue of credibility and trust in the marketplace. In general, there is a lack of awareness among producers, retailers, and consumers of the wider extent of organic production and processing standards in local markets [8].

\section{Conclusions}

The recent progress of the organic food industry has compelled the Malaysian Agricultural Research and Development Institute to actively develop the organic farming sector through various programs and activities. Organic food has been considered a new industry that contributes to economic growth. The production of organic food has become an innovative strategy for the Malaysian agricultural structure to sustain its competitive advantages. It was timely for the Malaysian government to review its organic farming policy and change its paradigm to ensure that the organic food industry becomes the engine of growth for the agricultural sector. The success of establishing this industry demands comprehensive strategies and collaboration from the government, producers, and marketers.

Acknowledgments: The authors would like to thank University of Malaya for supporting this research.

Author Contributions: All authors have contributed equally towards the research and the writing of the paper.

Conflicts of Interest: The authors declare no conflict of interest.

\section{References}

1. Mohamad, S.S.; Rusdi, S.D.; Hashim, N.H. Organic food consumption among urban consumers: Preliminary results. Procedia Soc. Behav. Sci. 2014, 130, 509-514. [CrossRef]

2. Dardak, R.A.; Abidin, A.Z.Z.; Ali, A.K. Consumers' perception, comsumption, and preference on organic product: Malaysian perspective. Econ. Technol. Manag. Rev. 2009, 4, 95-107.

3. A New Beginning for Organic Food Industry. Available online: http://www.asean.org/communities (accessed on 7 August 2015).

4. Organic Food Standards and Labels: The Facts. Available online: http://www.ams.usda.gov (accessed on 6 August 2015).

5. Willer, H.; Lernoud, J. The World of Organic Agriculture: Statistics and Emerging Trends 2015; Research Institute of Organic Agriculture (FiBL): Frick, Switzerland; IFOAM-Organics International: Bonn, Germany, 2015. 
6. Tiraieyari, N.; Hamzah, A.; Samah, B.A. Organic Farming and Sustainable Agriculture in Malaysia: Organic Farmers' Challenges towards Adoption Asian Social Science. Asian Soc. Sci. 2014. [CrossRef]

7. Stanton, E.S. Malaysia's Markets for Functional Foods, Nutraceuticals and Organic Foods: An Introduction for Canadian Producers and Exporters. The Counsellor and Regional Agri-Food Trade Commissioner, Southeast Asia, and the High Commission of Canada in Malaysia; Agriculture and Agri-Food Canada: Ottawa, ON, Canada, 2011.

8. Saleki, Z.S.; Saleki, S.M.S. The main factors influencing purchase behaviour of organic products in Malaysia. Interdiscip. J. Contemp. Res. Bus. 2012, 4, 98-116.

(C) 2016 by the authors; licensee MDPI, Basel, Switzerland. This article is an open access article distributed under the terms and conditions of the Creative Commons Attribution (CC-BY) license (http://creativecommons.org/licenses/by/4.0/). 